\title{
Continuous-flow synthesis of primary amines: Metal-free reduction of aliphatic and aromatic nitro derivatives with trichlorosilane
}

\author{
Riccardo Porta, Alessandra Puglisi ${ }^{*}$, Giacomo Colombo, Sergio Rossi \\ and Maurizio Benaglia*
}

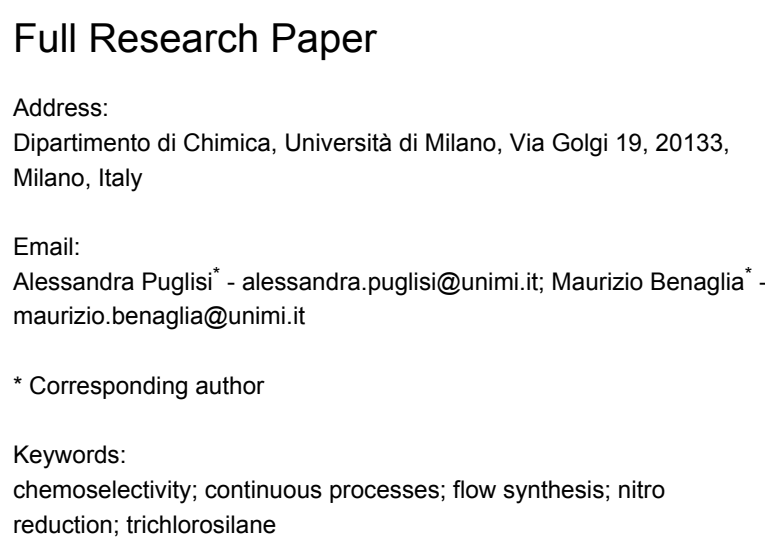

Beilstein J. Org. Chem. 2016, 12, 2614-2619. doi:10.3762/bjoc. 12.257

Received: 29 September 2016

Accepted: 23 November 2016

Published: 05 December 2016

This article is part of the Thematic Series "Green chemistry".

Guest Editor: L. Vaccaro

(c) 2016 Porta et al.; licensee Beilstein-Institut. License and terms: see end of document.

\begin{abstract}
The metal-free reduction of nitro compounds to amines mediated by trichlorosilane was successfully performed for the first time under continuous-flow conditions. Aromatic as well as aliphatic nitro derivatives were converted to the corresponding primary amines in high yields and very short reaction times with no need for purification. The methodology was also extended to the synthesis of two synthetically relevant intermediates (precursors of baclofen and boscalid).
\end{abstract}

\section{Introduction}

The reduction of nitro compounds to amines is a fundamental transformation in organic synthesis. The nitration of aromatic rings followed by reduction is the most classical entry for the preparation of anilines [1,2]. Lately, also aliphatic nitro derivatives have become more and more popular: a wide variety of highly functionalized and chiral aliphatic nitro compounds, precursors of the corresponding chiral amines, are accessible via several synthetic routes. In the last years nitro compounds have been the subject of numerous studies since they served as reactants in many, highly efficient, organocatalytic transformations [3-7]. Furthermore, the introduction of an amino group offers a well-known plethora of further synthetic elaborations.
Among the different available methodologies for the reduction of nitro compounds [8], we have recently reported a very convenient, mild, metal-free and inexpensive procedure, of wide applicability $[9,10]$. The simple combination of trichlorosilane $\left(\mathrm{HSiCl}_{3}\right)$ and a tertiary amine generates in situ a dichlorosilylene species which is the actual reducing species [11].

Even though nitro derivatives are fundamental building blocks in organic synthesis, their application on a large scale is still quite limited because they are dangerous and potentially explosive chemicals. Flow chemistry has recently emerged as a powerful technology in synthetic chemistry [12] as it can reduce 
risks associated to the use of hazardous chemicals and favors reaction scale-up [13-17]. The possibility to efficiently perform nitro reduction in continuo would make the transformation safer and more appealing in view of an industrial application and a possible scale-up of the process [18-20].

Herein we report a very convenient, metal-free reduction of both aromatic and aliphatic nitro derivatives, including chiral compounds, to amines with $\mathrm{HSiCl}_{3}$ under continuous-flow conditions.

Typically, the transformation of nitro compounds to amines under continuous-flow conditions is performed through the metal-catalyzed hydrogenation [21-23] with ThalesNano $\mathrm{H}-\mathrm{Cube}^{\circledR}$, which exploits $\mathrm{H}_{2}$ generated in situ by water electrolysis [24]. The procedure involves relatively mild reaction conditions, but the presence of noble metal catalysts, packed into disposable cartridges, suffers from functional group compatibility and catalyst poisoning during time.

In 2012 Kappe's research group reported the microwaveassisted continuous-flow synthesis of anilines from nitroarenes using hydrazine as reducing agent and iron oxide nanocrystals as the catalyst [25]. This methodology ensured fast transformations ( 2 to 8 minutes) of a wide number of substrates and was extended to large scale preparation of pharmaceutically relevant anilines [26]. However, this procedure required harsh reaction conditions $\left(T=150{ }^{\circ} \mathrm{C}\right)$, is limited to aromatic substrates and could not be applied to compounds bearing ketones or aldehydes as functional groups.

In the present work we provide an alternative continuous-flow metal-free methodology for the synthesis of both aliphatic and aromatic amines, which requires inexpensive reagents, mild and fast reaction conditions $\left(25^{\circ} \mathrm{C}, 5\right.$ minutes $)$, and a very simple and user-friendly reaction set-up.

\section{Results and Discussion}

In our methodology, a nitro derivative is reacted with commercially available $\mathrm{HSiCl}_{3}$ in the presence of a tertiary base (typically Hünig's base) in an organic solvent (typically $\mathrm{CH}_{2} \mathrm{Cl}_{2}$, although $\mathrm{CH}_{3} \mathrm{CN}$ affords comparable results). The continuousflow reduction of 4-nitrobenzophenone (1a) was chosen as model reaction. A syringe pump equipped with two gas-tight $2.5 \mathrm{~mL}$ syringes was used to feed the reagents into a $0.5 \mathrm{~mL}$ PTFE reactor (i.d. $=0.58 \mathrm{~mm}, l=189 \mathrm{~cm}$ ) through a T-junction (syringe A: $0.8 \mathrm{M}$ solution of $\mathrm{HSiCl}_{3}$ in $\mathrm{CH}_{2} \mathrm{Cl}_{2}$; syringe $\mathrm{B}$ : $0.2 \mathrm{M}$ solution of $\mathbf{1 a}$ in $\mathrm{CH}_{2} \mathrm{Cl}_{2}$, Hünig's base 6 equiv, Scheme 1).

The outcome of the reactor was collected into a flask containing $10 \% \mathrm{NaOH}$ solution in order to quench the reaction. After phase separation the crude reaction mixture was analyzed by ${ }^{1} \mathrm{H}$ NMR to determine the conversion. When the reaction reached a full conversion ( $>98 \%$ ) no further purification step was required and the aniline was recovered as clean product after simple concentration of the organic phase and extraction with ethyl acetate. A screening of flow rates was initially performed and the results are reported in Table 1.

As data show, the reaction is very fast and a complete conversion of nitroarene 1a to aniline $\mathbf{2 a}$ was achieved with very short residence times (10, 5 and $2.5 \mathrm{~min}$, Table 1 , entries $1-3)$. With a 1.2 minutes residence time, $91 \%$ conversion was reached. The faster reaction in the flow process compared to the batch one (5 minute vs 18 hours [8]) can be partially attributed to the higher reaction temperature: the flow reaction can be performed at $25{ }^{\circ} \mathrm{C}$ while the batch reaction required a cooling to $0{ }^{\circ} \mathrm{C}$, at least at the beginning of the reaction (the first few hours).

Having demonstrated that the flow transformation is very fast we next explored reaction scale-up employing a bigger flow

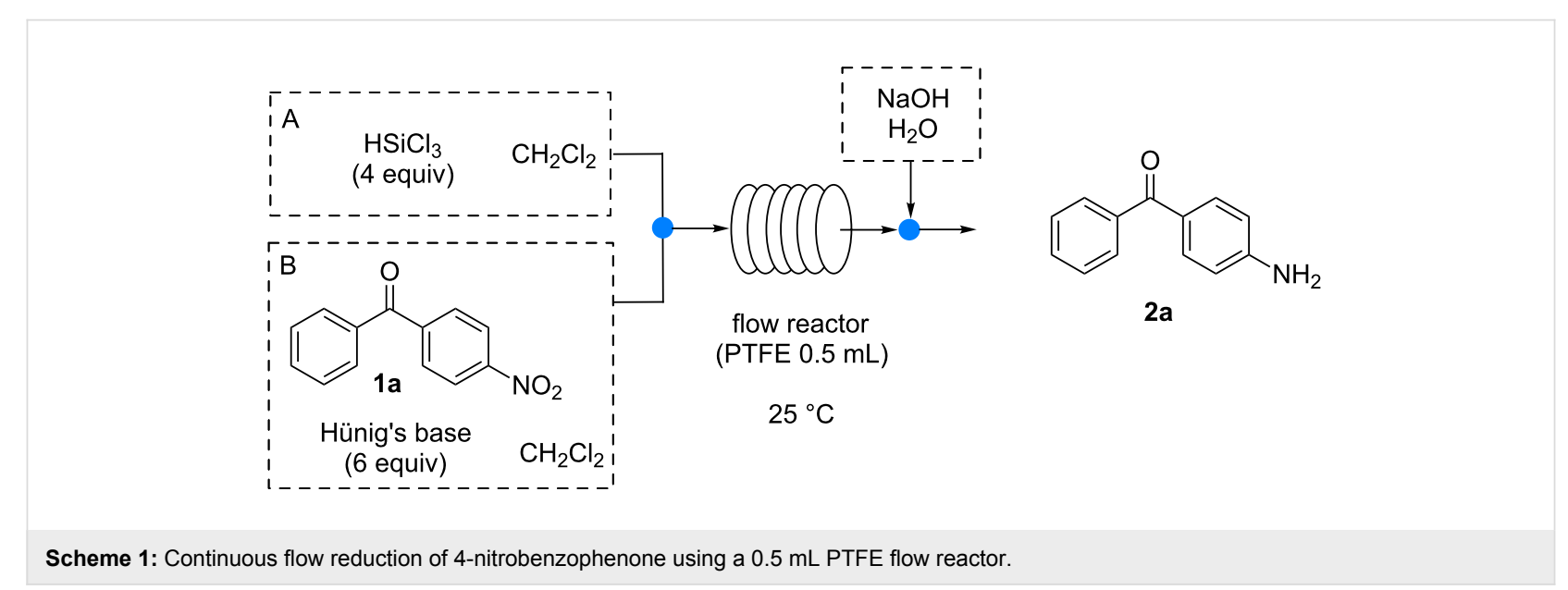


Table 1: Screening of reaction conditions.

\begin{tabular}{llll} 
Entry $^{\mathrm{a}}$ & $\begin{array}{l}\text { Flow rate } \\
(\mathrm{mL} / \mathrm{min})\end{array}$ & $\begin{array}{l}\text { Residence } \\
\text { time }(\mathrm{min})\end{array}$ & $\begin{array}{l}\text { Conversion } \\
(\%)^{\mathrm{b}}\end{array}$ \\
\hline 1 & 0.05 & 10 & $98(96)$ \\
2 & 0.1 & 5 & $98(96)$ \\
3 & 0.2 & 2.5 & $98(93)$ \\
4 & 0.4 & 1.2 & $91(85)$ \\
$5^{\mathrm{c}}$ & 0.1 & 50 & 97 \\
$6^{\mathrm{c}, \mathrm{d}}$ & 0.1 & 50 & 87 \\
$7^{\mathrm{c}}$ & 0.2 & 25 & 82 \\
\hline
\end{tabular}

${ }^{a}$ Reaction performed using a $0.2 \mathrm{M}$ solution of $\mathrm{Ar}-\mathrm{NO}_{2}(0.6 \mathrm{mmol})$ in $\mathrm{CH}_{2} \mathrm{Cl}_{2}, \mathrm{HSiCl}_{3}$ (4 equiv), Hünig's base (6 equiv) at room temperature ${ }^{b}$ reaction conversion determined by NMR of the crude; isolated yields in parentheses; ${ }^{c}$ reaction performed in a $5 \mathrm{~mL}$ PTFE reactor; ${ }^{d}$ reaction performed using TEA as a base.

reactor $(5 \mathrm{~mL}$ PTFE reactor, i.d. $=2.54 \mathrm{~mm}, l=100 \mathrm{~cm})$, in order to increase the productivity of the process.

Using the same reaction set-up illustrated in Scheme 1, a residence time of 50 minutes was necessary to reach a full conversion of the starting material (Table 1 , entry 5 ). This is mainly due to the bigger internal diameter of the reactor $(2.54 \mathrm{~mm}$ vs $0.58 \mathrm{~mm}$ ) which affects the mixing of the reagents [27,28]. Lowering the residence time resulted in minor conversions (Table 1, entry 7, 25 min residence time, $82 \%$ conversion). A cheaper base than Hünig's base as TEA (triethylamine) could also effectively promote the reduction with only marginally lower conversion (Table 1, entry 6 vs entry 5) [9-11]. The possibility to use commercially available $\mathrm{HSiCl}_{3}$, in combination with an inexpensive base as TEA, and the simple work-up make this very mild reduction methodology appealing for several future synthetic applications, also of industrial interest.

We next focused on expanding the scope of the reaction and proof the general applicability. Using both $0.5 \mathrm{~mL}$ and $5 \mathrm{~mL}$ reactors, under the best reaction conditions, the continuous-flow reduction of different nitroarenes was studied (Scheme 2).

As already demonstrated for the batch procedure [8], the reaction in continuo tolerates a large variety of functional groups: aromatic nitro groups are selectively reduced with quantitative conversions in the presence of ketones (Table 2, entry 1 ), halogens (Table 2, entries 3-5) and esters (Table 2, entry 6).

Scheme 2: Continuous flow reduction of aromatic nitro compounds

Table 2: Scope of the reaction (see Scheme 2).

\begin{tabular}{|c|c|c|c|}
\hline Entry $^{a}$ & $\mathrm{R}$ & $\begin{array}{l}0.5 \mathrm{~mL} \text { Reactor } \\
\left.\text { Conversion }^{\mathrm{b}} \%\right)^{\mathrm{c}}\end{array}$ & $\begin{array}{l}5 \mathrm{~mL} \text { Reactor } \\
\text { Conversion }(\%)^{\mathrm{e}}\end{array}$ \\
\hline 1 & 4-nitrobenzoyl, 1a & $98(96)$ & 97 \\
\hline 2 & 4-Me, 1b & $98(96)$ & 98 \\
\hline 3 & $4-\mathrm{Br}, 1 \mathrm{c}$ & $98(92)$ & 98 \\
\hline 4 & $2,4-\mathrm{Cl}_{2}, 1 \mathrm{~d}$ & $98(92)$ & 92 \\
\hline 5 & $4-F, 1 e$ & $98(90)$ & 91 \\
\hline 6 & 4-COOMe, $1 f$ & $98(95)$ & 98 \\
\hline
\end{tabular}

aReaction performed using a $0.2 \mathrm{M}$ solution of $\mathrm{Ar}-\mathrm{NO}_{2}$ in $\mathrm{CH}_{2} \mathrm{Cl}_{2}, \mathrm{HSiCl}_{3}$ (4 equiv), Hünig's base (6 equiv) at room temperature; ${ }^{\circ} \mathrm{Residence} \mathrm{time} \mathrm{=}$ $5 \mathrm{~min}$; ${ }^{\mathrm{R}}$ Reaction conversion determined by NMR of the crude; isolated yield in parenthesis; ${ }^{\mathrm{d}}$ Residence time $=50 \mathrm{~min}$; ${ }^{\mathrm{e}} \mathrm{Determined}$ by NMR of the crude. 
The methodology was also extended to aliphatic nitro compounds (Scheme 3). These substrates are less reactive than aromatic ones and they typically require higher hydrogen pressures or reaction temperatures to be completely reduced to the corresponding aliphatic amines.

By employing our metal-free methodology, at $25^{\circ} \mathrm{C}$ in a $0.5 \mathrm{~mL}$ reactor, aliphatic amines $2 \mathrm{~g}$ and $2 \mathrm{~h}$ were obtained with a full conversion of the starting material and isolated yields of $91 \%$ and $93 \%$, respectively, by using a residence time of 10 minutes only (when a residence time of 5 minutes was used a slightly lower yield was obtained $-81 \%$ for amine $\mathbf{2 g}$ ).

We then applied the trichlorosilane-mediated continuous-flow nitro reduction to the synthesis of advanced precursors of molecules of pharmaceutical interest. The reduction of nitro compound 3 afforded 2-(4'-chlorophenyl)aniline (4), the direct precursor of the fungicide boscalid (Scheme 4). Under the best reaction conditions in a $5 \mathrm{~mL}$ PTFE reactor (flow rate $0.1 \mathrm{~mL} / \mathrm{min}, 50 \mathrm{~min}$ residence time), the desired amine 4 was obtained in quantitative yield as a clean product with no need for purification.

We also investigated the continuous-flow reduction of nitro ester $\mathbf{5}$, which can be conveniently prepared in one step through the organocatalyzed addition of diethyl malonate to trans- $\beta$ nitrostyrene promoted by a chiral thiourea [29]. The corresponding amide 6 is a direct precursor of the GABA receptor agonist Baclofen (Scheme 5).

Nitro compound 5 was continuously reduced in a $5 \mathrm{~mL}$ reactor and, after work-up under neutral conditions, chiral lactam 6 was isolated in $48 \%$ yield.

Finally we explored the possibility of performing a reaction scale-up, followed by an in-line extraction in order to obtain a

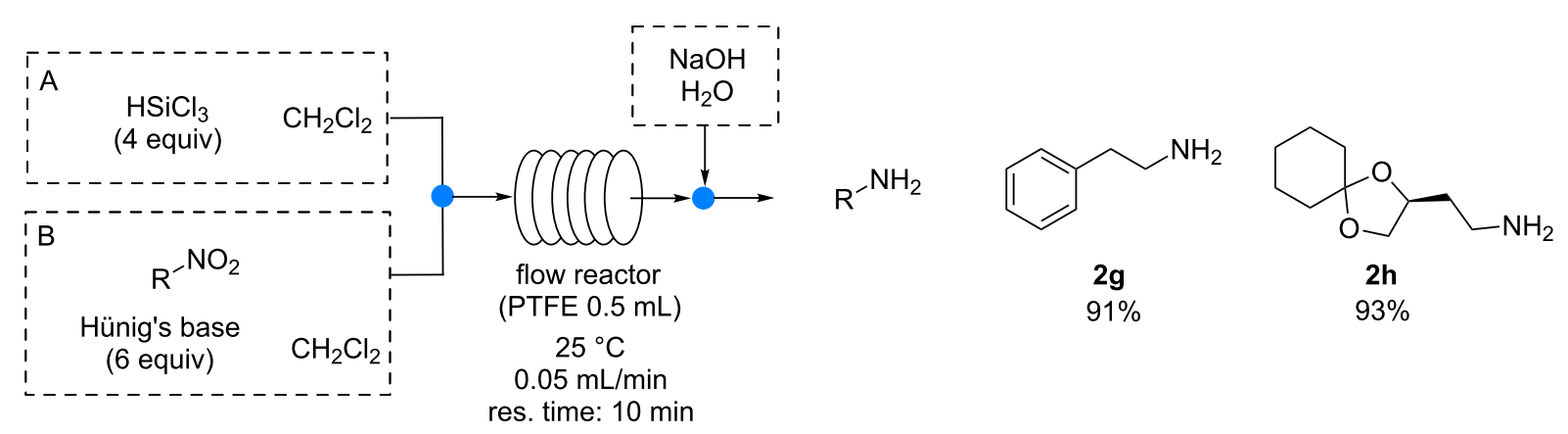

Scheme 3: Continuous-flow reduction of aliphatic nitro compounds.

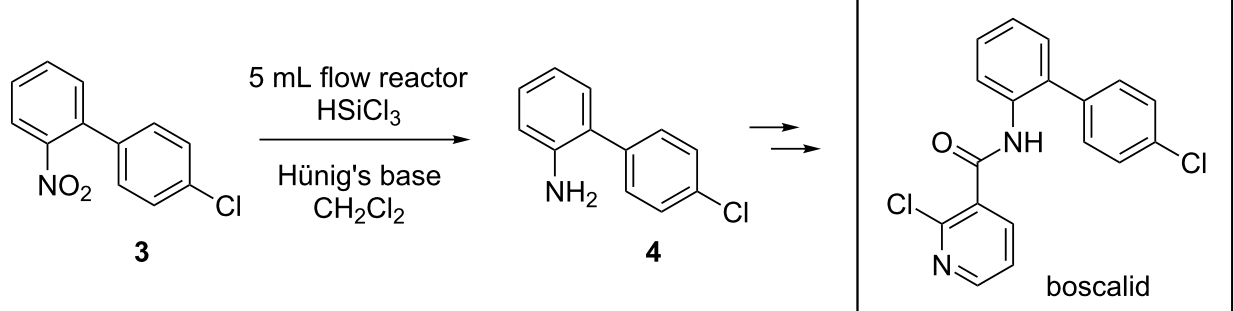

Scheme 4: Synthesis of 2-(4'-chlrophenyl)aniline (4) with a $5 \mathrm{~mL}$ flow reactor.
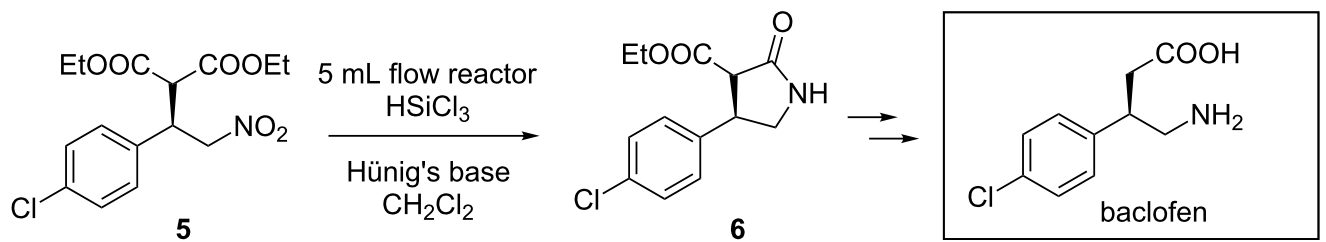

Scheme 5: Synthesis of intermediate 6, a direct precursor of the drug baclofen 
full continuous process with no need for intermediate operations (Scheme 6).

A syringe pump equipped with two SGE gas tight $25 \mathrm{~mL}$ syringes was used to feed the reagents into a $5 \mathrm{~mL}$ PTFE reactor through a T-junction (syringe $\mathrm{A}: \mathrm{HSiCl}_{3}(24 \mathrm{mmol})$ in $15 \mathrm{~mL}$ $\mathrm{CH}_{2} \mathrm{Cl}_{2}$; syringe $\mathrm{B}$ : substrate 1a $(6 \mathrm{mmol})$, Hünig's base (36 mmol in $15 \mathrm{~mL} \mathrm{CH}_{2} \mathrm{Cl}_{2}$ )) with a flow rate of $0.1 \mathrm{~mL} / \mathrm{min}$ (residence time $50 \mathrm{~min}$ ). The outcome of the reactor was collected into a separatory funnel containing $\mathrm{NaOH} 10 \%$ solution $(10 \mathrm{~mL})$ and $\mathrm{CH}_{2} \mathrm{Cl}_{2}(10 \mathrm{~mL})$. The biphasic system was kept under stirring and the organic layer was continuously collected into a flask. Removal of $\mathrm{CH}_{2} \mathrm{Cl}_{2}$ gave pure amino compound 2a in $94 \%$ yield. This system allowed to easily obtaining almost $1 \mathrm{~g}$ of pure $\mathbf{2 a}$ in about 4 hours (see Supporting Information File 1 for further details).

\section{Conclusion}

In conclusion, a very convenient, mild, metal-free reduction of aliphatic and aromatic nitro derivatives under continuous flowconditions has been successfully developed. The general applicability to differently substituted compounds and the possibility to scale-up the process have been demonstrated. The use of extremely inexpensive and non-hazardous chemicals, the very high chemoselectivity and the possibility to realize a completely automated reduction/work-up/isolation process are distinctive features that make the protocol suitable for the reduction of a large variety of products and attractive also for future industrial applications.

\section{Experimental}

General procedure for the continuous-flow reaction using a $0.5 \mathrm{~mL}$ PTFE reactor: Syringe A was filled with a solution of $\mathrm{HSiCl}_{3}(2.4 \mathrm{mmol})$ in dry $\mathrm{CH}_{2} \mathrm{Cl}_{2}(1.5 \mathrm{~mL})$. Syringe B was loaded with a solution of the nitro compound $(0.6 \mathrm{mmol})$ and Hünig's base $(3.6 \mathrm{mmol})$ in dry $\mathrm{CH}_{2} \mathrm{Cl}_{2}(1.5 \mathrm{~mL})$. Syringes A and $\mathrm{B}$ were connected to a syringe pump and the reagents were pumped into the microreactor at the indicated flow rate
$(\mathrm{mL} / \mathrm{min})$ at room temperature. The outcome of the reactor was collected in a flask containing a $10 \% \mathrm{NaOH}$ solution. Five reactor volumes were collected. $\mathrm{CH}_{2} \mathrm{Cl}_{2}$ was removed in vacuo and the aqueous layer was extracted three times with ethyl acetate. The combined organic layers were washed with brine, dried with $\mathrm{Na}_{2} \mathrm{SO}_{4}$ and concentrated in vacuo. ${ }^{1} \mathrm{H}$ NMR spectroscopy of the crude was used to calculate the reaction conversion; in case of a full conversion of the starting material no further purification was required.

\section{Supporting Information}

\section{Supporting Information File 1}

General procedure for continuous-flow reactions, products characterization and NMR spectra of the compounds. [http://www.beilstein-journals.org/bjoc/content/ supplementary/1860-5397-12-257-S1.pdf]

\section{Acknowledgements}

A.P. thanks the University of Milan for the grant "Piano di Sostegno alla Ricerca 2015-17 - LINEA 2 Azione A (Giovani Ricercatori)". M.B. thanks the University of Milan for the Transition Grant 2015-17-Horizon 2020. R.P. thanks the University of Milan for a Ph.D. fellowship. S.R. thanks the University of Milan for a postdoctoral fellowship.

\section{References}

1. Blaser, H. U.; Siegrist, U.; Steiner, H.; Studer, M. In Fine chemicals through Heterogeneous Catalysis; Sheldon, R. A.; van Bekkum, H., Eds.; Wiley-VCH: Weinheim, 2001; pp 389-471.

See for an overview on synthetic aspects of the catalytic reduction of nitroarenes.

2. Blaser, H.-U.; Steiner, H.; Studer, M. ChemCatChem 2009, 1, 210-221. doi:10.1002/cctc.200900129

3. Ballini, R.; Bosica, G.; Fiorini, D.; Palmieri, A.; Petrini, M. Chem. Rev. 2005, 105, 933-972. doi:10.1021/cr040602r

4. Noble, A.; Anderson, J. C. Chem. Rev. 2013, 113, 2887-2939. doi:10.1021/cr300272t

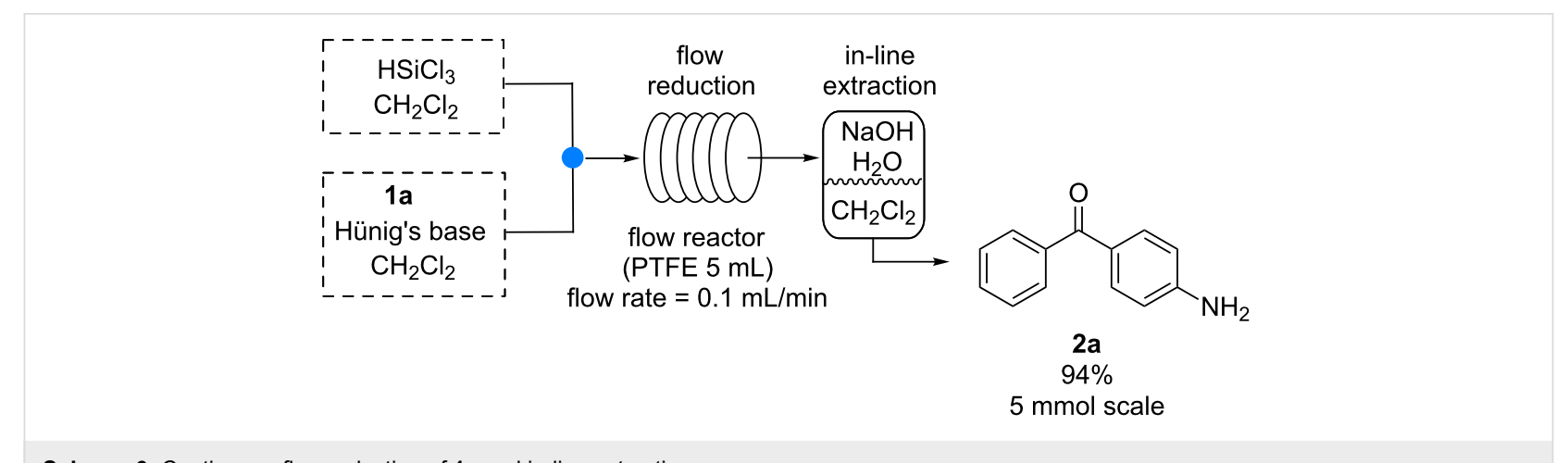


5. Roca-Lopez, D.; Sabada, D.; Delso, I.; Herrera, R. P.; Tejero, P.; Merino, P. Tetrahedron: Asymmetry 2010, 21, 2561-2601. doi:10.1016/j.tetasy.2010.11.001

6. Mukherjee, S.; Yang, J. W.; Hoffmann, S.; List, B. Chem. Rev. 2007, 107, 5471-5569. doi:10.1021/cr0684016

7. Enders, D.; Wang, C.; Liebich, J. X. Chem. - Eur. J. 2009, 15, 11058-11076. doi:10.1002/chem.200902236

See for a review on organocatalytic asymmetric conjugate additions.

8. Orlandi, M.; Brenna, D.; Harms, R.; Jost, S.; Benaglia, M. Org. Process Res. Dev. 2016. doi:10.1021/acs.oprd.6b00205 See for a recent review.

9. Orlandi, M.; Tosi, F.; Bonsignore, M.; Benaglia, M. Org. Lett. 2015, 17, 3941-3943. doi:10.1021/acs.orglett.5b01698

10. The methodology is also described in a patent: International Patent Application: Bonsignore, M.; Benaglia, M. PCT/EP/2013/06837 (05.09.2013) (Università degli Studi di Milano, Milano, Italy), now owned by DexLeChem GmbH (Berlin, Germany).

11. Orlandi, M.; Benaglia, M.; Tosi, F.; Annunziata, R.; Cozzi, F. J. Org. Chem. 2016, 81, 3037-3041. doi:10.1021/acs.joc.6b00191

12. Gutmann, B.; Cantillo, D.; Kappe, C. O. Angew. Chem., Int. Ed. 2015, 54, 6688-6728. doi:10.1002/anie.201409318

13. Atodiresei, I.; Vila, C.; Rueping, M. ACS Catal. 2015, 5, 1972-1985. doi:10.1021/acscatal.5b00002

14. Puglisi, A.; Benaglia, M.; Porta, R.; Coccia, F. Curr. Organocatal. 2015, 2, 79-101. doi:10.2174/2213337202666150513002701

15. Munirathinam, R.; Huskens, J.; Verboom, W. Adv. Synth. Catal. 2015, 357, 1093-1123. doi:10.1002/adsc.201401081

16. Rodríguez-Escrich, C.; Pericàs, M. A. Eur. J. Org. Chem. 2015, 1173-1188. doi:10.1002/ejoc.201403042

17. Porta, R.; Benaglia, M.; Puglisi, A. Org. Process Res. Dev. 2016, 20 , 2-25. doi:10.1021/acs.oprd.5b00325

18. Poh, J.-S.; Tran, D. N.; Battilocchio, C.; Hawkins, J. M.; Ley, S. V. Angew. Chem., Int. Ed. 2015, 54, 7920-7923. doi:10.1002/anie.201501538

19. Fabry, D. C.; Ronge, M. A.; Rueping, M. Chem. - Eur. J. 2015, 21 , 5350-5354. doi:10.1002/chem.201406653

20. Tran, D. N.; Battilocchio, C.; Lou, S.-B.; Hawkins, J. M.; Ley, S. V. Chem. Sci. 2015, 6, 1120-1125. doi:10.1039/C4SC03072A

21. Cossar, P. J.; Hizartzidis, L.; Simone, M. I.; McCluskey, A.; Gordon, C. P. Org. Biomol. Chem. 2015, 13, 7119-7130. doi:10.1039/C5OB01067E

22. Hartwig, J.; Ceylan, S.; Kupracz, L.; Coutable, L.; Kirschning, A. Angew. Chem., Int. Ed. 2013, 52, 9813-9817. doi:10.1002/anie.201302239

23. Tsubogo, T.; Oyamada, H.; Kobayashi, S. Nature 2015, 520, 329-332. doi:10.1038/nature14343

24. Jones, R. V.; Godorhazy, L.; Varga, N.; Szalay, D.; Urge, L.; Darvas, F. J. Comb. Chem. 2006, 8, 110-116. doi:10.1021/cc050107o

25. Cantillo, D.; Baghbanzadeh, M.; Kappe, C. O. Angew. Chem., Int. Ed. 2012, 51, 10190-10193. doi:10.1002/anie.201205792

26. Cantillo, D.; Moghaddam, M. M.; Kappe, C. O. J. Org. Chem. 2013, 78, 4530-4542. doi:10.1021/j0400556g

27. Hartman, R. L.; McMullen, J. P.; Jensen, K. F. Angew. Chem., Int. Ed. 2011, 50, 7502-7519. doi:10.1002/anie.201004637

28. Elvira, K. S.; Casadevall i Solvas, X.; Wootton, R. C. R.; deMello, A. J. Nat. Chem. 2013, 5, 905-915. doi:10.1038/nchem.1753

29. Okino, T.; Hoashi, Y.; Furukawa, T.; Xu, X.; Takemoto, Y. J. Am. Chem. Soc. 2005, 127, 119-125. doi:10.1021/ja044370p

\section{License and Terms}

This is an Open Access article under the terms of the Creative Commons Attribution License

(http://creativecommons.org/licenses/by/4.0), which permits unrestricted use, distribution, and reproduction in any medium, provided the original work is properly cited.

The license is subject to the Beilstein Journal of Organic Chemistry terms and conditions:

(http://www.beilstein-journals.org/bjoc)

The definitive version of this article is the electronic one which can be found at:

doi:10.3762/bjoc. 12.257 